\title{
VALIDAÇÃO DE CONTEÚDO E APARÊNCIA DE MATERIAL DIDÁTICO PARA FAMILIARES DE CRIANÇAS SUBMETIDAS À CATETERIZAÇÃO VENOSA PERIFÉRICA
}

\author{
, Cleonara Sousa Gomes e Silva ${ }^{1}$, Silvone Santa Barbara da Silva Santos ${ }^{2}$ e Luciano \\ Marques dos Santos ${ }^{3}$ e Manuela de Jesus Souza ${ }^{4}$ \\ 2. Bolsista PIBIC/CNPq, Graduanda em Enfermagem, Universidade Estadual de Feira de Santana, e-mail: \\ cleosilvauefs@gmail.com \\ 3. Orientadora, Departamento de Saúde Universidade Estadual de Feira de Santana, e-mail: \\ silvone.santabarbara@gmail.com \\ 4. Coordenador do projeto "Segurança do paciente pediátrico e sua família: estudo de tecnologias e evento adverso \\ associado a terapia intravascular periférica", Departamento de Saúde, Universidade Estadual de Feira de Santana, e- \\ mail: lucmarxenfo@yahoo.com.br \\ 1. Participante do projeto "Segurança do paciente pediátrico e sua família: estudo de tecnologias e evento adverso \\ associado a terapia intravascular periférica", Departamento de Saúde, Universidade Estadual de Feira de Santana, e- \\ mail: maanusouzauefs@gmail.com
}

PALAVRAS-CHAVE: Enfermagem Pediátrica; Tecnologia Educacional; Cateterismo venoso periférico

\section{INTRODUÇÃO}

A utilização de materiais didáticos e instrucionais por familiares acompanhantes de crianças hospitalizadas são de extrema importância para auxiliá-los na compreensão de determinadas temáticas, como a Cateterização Intravenosa Periférica (CIP) em crianças.

Em estudo realizado por Bezerra et al (2009) percebeu-se que os familiares sentem a necessidade de receber informações claras e objetivas sobre a CIP em criança, desse modo, eles saberiam o que fazer durante o procedimento.

Uma maneira de articular esse cuidado ao familiar é através da utilização de materiais e métodos que contenham informações sobre a CIP em crianças. Um exemplo disso é cartilha "Punção venosa periférica para família".

No entanto, tal tecnologia necessita passar pelo processo de validação, para verificar se o material oferece o conteúdo necessário para amenizar as dúvidas dor familiar sobre a temática de forma que facilite o seu entendimento. Sendo assim, o objetivo desse estudo é validar o conteúdo e a aparência da tecnologia didática e instrucional intitulada "Punção venosa periférica para família" junto à experts da área pediátrica.

O interesse para a realização desse estudo deve-se ao tentar estabelecer o estado da arte em periódicos nacional e internacional sobre o preparo de familiares acompanhantes de crianças hospitalizadas submetidas à CIP, através de manuais instrucionais validados, no período de outubro à dezembro de 2015 na Biblioteca Virtual em Saúde (BVS), PUBMED, Science Direct, SCOPUS, Web of Science e CUIDEN, utilizando os descritores em saúde: Família, Enfermagem Pediátrica, Enfermagem Familiar, Criança Hospitalizada, Tecnologia Educacional, Material de Ensino, Cateterismo Periférico, Segurança do Paciente, Infusões Intravenosas e Estudos de Validação, além de seus correspondentes em inglês e espanhol, e os semelhantes do Medical Subject Headings (MESH). Foram encontrados 2 artigos (Benchaya; Ferreira; Brasiliense, 2014; Bezerra et al. 2009).

Frente ao exposto, questiona-se a Cartilha "Punção venosa periférica para família" tem validade de conteúdo? 


\section{MATERIAL E MÉTODOS}

Trata-se de um estudo metodológico do tipo elaboração de tecnologia, realizado em 2016. A validação de conteúdo da cartilha foi realizada por 7 profissionais de saúde, considerados experts da temática, sendo utilizada a técnica Delphi (SCARPARO et al., 2012). Foram avaliadas as seguintes categorias: conteúdo, linguagem, ilustração, layout, motivação, cultura e aplicabilidade. (Oliveira; Pagliuca, 2013; OLIVEIRA; LOPES. Fernandes, 2014). Com relação ao nível de consenso entre as respostas foi adotado como Índice de Validação de Aparência (IVA) valor igual ou superior a 0,80 (Perroca, 2011; Scarparo et al., 2012; Avelar; Pedreira; Peterlini, 2013). Este estudo foi aprovado pelo Comitê de Ética na Pesquisa da Universidade Estadual de Feira de Santana através do parecer 841612 .

\section{RESULTADOS}

A cartilha "Punção venosa periférica para família" foi validada na primeira rodada de avaliação pelos experts. Obteve IVA maior que 0,80 em todas as variáveis, tendo com IVA global 0,98. Nas tabelas 1, 2, 3 e 4 apresentam os índices das categorias de conteúdo, linguagem, ilustração, layout, motivação, cultura e aplicabilidade.

\begin{tabular}{|c|c|c|c|c|c|}
\hline Vanavers & $\begin{array}{c}\text { Pagruas 03 evs } \\
\text { (Conversa dos familiares } \\
\text { sobre as experiências deles } \\
\text { a cerca da cateterizaçăo } \\
\text { intravenosa periférica nas } \\
\text { crianças.) }\end{array}$ & $\begin{array}{l}\text { Pagiuas U0 a US } \\
\text { (Conversa da } \\
\text { enfermeira com } \\
\text { os familiares) }\end{array}$ & $\begin{array}{l}\text { Pagina 09 a II } \\
\text { (Orientaçăo da enfermeira } \\
\text { a os familiares sobre veia, } \\
\text { cateter e motivo da } \\
\text { realizaçăo da CIP nas } \\
\text { crianças.) } \\
\end{array}$ & $\begin{array}{l}\text { Paginas I2 a I3 } \\
\text { (Explicaçáo da } \\
\text { enfermeira sobre o } \\
\text { passo a passo da CIP } \\
\text { para os familiares) }\end{array}$ & $\begin{array}{c}\text { Pagina 14 a 17 } \\
\text { (Estratégia para } \\
\text { minimizar o } \\
\text { estresse.) }\end{array}$ \\
\hline 1. Conteudo & "TVC & $\overline{7 T C}$ & "TVC & $=7 \sqrt{1 V C}$ & "TVC \\
\hline $\begin{array}{l}1.10 \text { conteudo está correto } \\
\text { cientificamente }\end{array}$ & 1,0 & 1.0 & 1,0 & 1,0 & 1,0 \\
\hline $\begin{array}{l}1.20 \text { conteudo esta apropriado a } \\
\text { público-alvo }\end{array}$ & 1,0 & 1.0 & 1,0 & 1,0 & 1,0 \\
\hline $\begin{array}{l}\text { 13 O conteudo é suficiente para } \\
\text { atender às necessidades do } \\
\text { público-alvo }\end{array}$ & 1,0 & 1,0 & 1,0 & 0,85 & 1,0 \\
\hline $\begin{array}{l}\text { 1.4 A sequência do texto é logica } \\
\text { 1.5 A apresentaçảo do conteudo } \\
\text { favorece a aprendizagen da } \\
\text { temática }\end{array}$ & $\begin{array}{l}1,0 \\
1,0\end{array}$ & $\begin{array}{c}0,85 \\
1,0\end{array}$ & $\begin{array}{l}1,0 \\
1,0\end{array}$ & $\begin{array}{l}1.0 \\
1.0\end{array}$ & $\begin{array}{c}0,85 \\
1,0\end{array}$ \\
\hline $\begin{array}{l}\text { **IVC Global } \\
\text { 1. Linguagem }\end{array}$ & 1,0 & 0,97 & 1,0 & 0,97 & 0,97 \\
\hline $\begin{array}{l}2.1 \text { O estilo da redação è } \\
\text { compativel com o publico-alvo }\end{array}$ & 1,0 & 1,0 & 1,0 & 1,0 & 1,0 \\
\hline $\begin{array}{l}22 \text { A escrita utilizada é atrativa } \\
23 \text { A linguagem do texto é claa e } \\
\text { objetiva }\end{array}$ & $\begin{array}{l}1,0 \\
1,0\end{array}$ & $\begin{array}{l}1,0 \\
1,0\end{array}$ & $\begin{array}{l}1,0 \\
1,0\end{array}$ & $\begin{array}{l}1,0 \\
1,0\end{array}$ & $\begin{array}{l}1,0 \\
1,0\end{array}$ \\
\hline$\star \star$ IVC & 1,0 & 1,0 & 1,0 & 1.0 & 1,0 \\
\hline
\end{tabular}

Apesar de a cartilha ser avaliada como valida, os profissionais de saúde fizeram algumas sugestões, a fim de melhorar aspectos quanto à ortográfica, síntese de discursos repetitivos, esclarecimento e descrição de tópicos relevante para a compreensão dos familiares e substituição de termos que facilitem o entendimento do público-alvo, além de serem retiradas as expressões consideradas inadequadas. Foram realizadas as alterações solicitadas, de acordo com a necessidade.

\section{DISCUSSÕES}

Segundo os juízes, o conteúdo da cartilha mostrava-se cientificamente correto, apropriado e suficiente para o público-alvo, possui sequencia lógica, além de favorecer a aprendizagem da temática. 
A linguagem da cartilha foi considerada compatível para o público alvo e a escrita utilizada é atrativa, sendo clara e objetiva. De acordo com os juízes as ilustrações estavam pertinentes com o conteúdo do material e elucidam o conteúdo, claras e transmitem facilidade de compreensão, adequadas, relevantes e possui qualidade gráfica.

Tabela 2 - Distribuição do Indice de Concordância e Validade de Conteúdo dos juízes segundo critério de ilustração da primeira rodada. Feira de Santana (BA), 2016.

\begin{tabular}{|c|c|c|c|c|c|}
\hline Variaveis & $\begin{array}{c}\text { Paginas 03 e } 05 \\
\text { (Conversa dos familiares } \\
\text { sobre as experiências deles } \\
\text { acerca da cateterização } \\
\text { intravenosa periférica nas } \\
\text { crianças.) }\end{array}$ & $\begin{array}{l}\text { Paginas } 06 \text { a } 08 \\
\text { (Conversa da } \\
\text { enfermeira com os } \\
\text { familiares) }\end{array}$ & $\begin{array}{l}\text { Pagina 09 a II } \\
\text { (Orientação da } \\
\text { enfermeira aos familiares } \\
\text { sobre veia, cateter e } \\
\text { motivo da realização da } \\
\text { CIP nas crianças.) }\end{array}$ & $\begin{array}{l}\text { Paginas 12 a 13 } \\
\text { (Explicação da } \\
\text { enfermeira sobre } \\
\text { o passo a passo da } \\
\text { CIP para os } \\
\text { familiares) }\end{array}$ & $\begin{array}{l}\text { Pagina 14 a 17 } \\
\text { (Estratégia } \\
\text { para } \\
\text { minimizar o } \\
\text { estresse.) }\end{array}$ \\
\hline 3. Ilustraçäo & *IVC & FIVC & *IVC & *IVC & "IVC \\
\hline $\begin{array}{l}3.1 \text { As ilustraçōes são } \\
\text { pertinentes com o conteúdo do } \\
\text { material e elucidam o conteúdo }\end{array}$ & 1,0 & 1,0 & 1,0 & 0,85 & 1,0 \\
\hline $\begin{array}{l}3.2 \text { As ilustraçōes sâo claras e } \\
\text { transmitem facilidade de } \\
\text { compreensảo }\end{array}$ & 1,0 & 1,0 & 1.0 & 1,0 & 1.0 \\
\hline $\begin{array}{l}3.3 \text { As ilustraçōes possuem } \\
\text { qualidade gráfica }\end{array}$ & 1,0 & 1,0 & 1.0 & 1,0 & 1.0 \\
\hline $\begin{array}{l}\text { 3.4 A quantidade de ilustraçóes } \\
\text { está adequada para o conteúdo } \\
\text { do material educativo }\end{array}$ & 1,0 & 1,0 & 1.0 & 1.0 & 1.0 \\
\hline $\begin{array}{l}\text { 3.5 A presença de cada uma } \\
\text { das figuras na cartilha é } \\
\text { relevante }\end{array}$ & 1,0 & 0,85 & 0,85 & 1,0 & 1.0 \\
\hline$*$ IVC Global & 1,0 & 0.97 & 0,97 & 0.97 & 1.0 \\
\hline
\end{tabular}

Tabela 3 - Distribuição do Indice de Concordância e Validade de Conteúdo dos juízes segundo critério de layout e motivação da primeira rodada. Feira de Santana (BA), 2016.

Variáveis

4. Layout

4.1 O tipo de letra utilizado facilita a leitura;

4.2 As cores aplicadas ao texto são pertinentes e facilitadoras para a leitura;

4.3 A composição visual está atrativa e bem organizada;

$4.4 \mathrm{O}$ formato (tamanho) do material educativo e o número de páginas estão adequados;

4.5 A disposição do texto está adequada;

4.6 O tamanho das letras dos títulos, subtítulos e texto é adequado;

4.7 O tamanho da cartilha está adequado;

**IVC Global

5 Motivação

5.1 O conteúdo está motivador e incentiva prosseguir a leitura

5.2 O conteúdo despertou o interesse do leitor

$5.3 \mathrm{O}$ conteúdo poderá atender às dúvidas, esclarecer e educar o familiar quanto a

punção venosa e estratégias para minimizar o estresse decorrente do

procedimento

**IVC Global

Fonte: Coleta de Dados

Validação de Conteúdo

Tabela 4 - Distribuição do Índice de Concordância e Validade de Conteúdo dos juízes segundo critério de layout e motivação da primeira rodada. Feira de Santana (BA), 2016.

Variáveis

6 Cultura

6.10 texto está compatível com o público-alvo, atendendo aos diferentes perfis

dos usuários

6.2 A cartilha está indicada para uso como recurso no preparo de familiares

hospitalizadas para a punção venosa periférica.

**IVC Global

7 Aplicabilidade

7.1 A cartilha possui aplicabilidade prática

$\therefore$ *IVC Global

Fonte: Coleta de Dados

*IVC: Índice de Validação de Conteúdo

**IVC Global: Índice de Validação de Conteúdo Global.

\begin{tabular}{c} 
*IVC \\
Individual \\
1,0 \\
0,85 \\
0,85 \\
1,0 \\
0,85 \\
1.0 \\
1,0 \\
$\mathbf{0 , 9 3}$ \\
1,0 \\
1,0 \\
1,0 \\
1,0 \\
\hline
\end{tabular}


Além disso, a cartilha apresenta aplicabilidade prática, o conteúdo motivava e incentiva a leitura, despertava o interesse do leitor e atende às dúvidas, esclarecer e educar o familiar quanto à punção venosa e estratégias para minimizar o estresse decorrente do procedimento.

Segundo Bezerra et al. (2009), os profissionais de saúde percebem os benefícios de fornecer informações para os familiares sobre a CIP na criança, pois proporciona tranquilidade e calma para os pais.

No entanto, de acordo como Ferreira et al. (2012) em estudo realizado com 59 familiares observou-se que 6,8\% deles disseram compreender como ocorre a CIP na criança e $37,2 \%$ relataram receber informações sobre o procedimento. Isso faz refletir o quanto a equipe de enfermagem ainda não despertou para o desenvolvimento de práticas direcionadas para Cuidado Centrado para a Família (CCF) no tocante a investir na utilização de materiais e métodos que aproxime o familiar do cuidado ao paciente pediátrico.

\section{CONCLUSÃO}

Através da validação foi possível analisar o material em vários aspectos, visando aprimorá-lo de maneira que o torna-se de fácil entendimento, prático e atrativo para os familiares, sendo contemplados assuntos de interesse do público alvo. Além de perceber que a cartilha é uma ferramenta útil para o profissional de enfermagem desenvolver educação em saúde por meio do CCF, pois quando o familiar adentra ao serviço de saúde torna-se um "protagonista" no processo de cuidado promovido pelo profissional.

\section{REFERÊNCIAS}

AVELAR, A. F. M.; PETERLINI, M. A. S.; PEDREIRA, M. L. G. 2013. Assertividade e tempo de permanência de cateteres intravenosos periféricos com inserção guiada por ultrassonografia em crianças e adolescentes. Rev. esc. enferm. USP 47( 3): 539-546. BENCHAYA, I; FERREIRA, E. A. P. BRASILIENSE, I. C. S. 2014. Efeitos de instrução e de treino parental em cuidadores de crianças com câncer. Psic.: Teor. $e$ Pesq. [online] 30 (1): 13-23.

BEZERRA, A. R. et al. 2009 “ Minha punção venosa periférica”: um material didáticoinstrucional no preparo da criança para o procedimento. Rev. Soc. Bras. Enferm. Ped. 9 (2): 77-85.

FERREIRA, M. J. M. et al. 2012. Cuidado da equipe de enfermagem à criança sob punção venosa periférica: estudo descritivo. Online Brazilian Journal of Nursing [serial on the Internet] 11 (1): 79-89.

OLIVEIRA, P. M. P. ; PAGLIUCA, L. M. F. 2013. Avaliação de tecnologia educativa na modalidade literatura de cordel sobre amamentação. Rev. esc. enferm. 47(1): 205-12. OLIVEIRA, S. C.; LOPES, M. V. O.; FERNANDES, A. F. C. 2014. Construção e validação de cartilha educativa para alimentação saudável durante a gravidez. Rev. Latino-Am. Enfermagem 22(4):611-620.

PERROCA, M. G. 2011. Desarrollo y validación de contenido de la nueva versión de un instrumento para clasificación de pacientes. Rev. Latino-Am. Enfermagem 19(1): 58 66.

SCARPARO, A. F. et al. Reflexões sobre o uso da Técnica de Delphi em pesquisas na Enfermagem. Rev Rene. 13(1): 242-5. 